\title{
DESIGN OF WORK HOLDING DEVICE ON WHEEL HUB FOR DRILLING OF 5 LUG BOLTS
}

\author{
Hamritha S \\ Assistant Professor, Industrial Engineering and Management, \\ Ramaiah Institute of Technology, Bangalore, India

\section{Rajesh B} \\ Student, Industrial Engineering and Management, \\ Ramaiah Institute of Technology, Bangalore, India

\section{Hemanth M} \\ Student, Industrial Engineering and Management, \\ Ramaiah Institute of Technology, Bangalore, India
}

\begin{abstract}
Work holding devices are a crucial part of the component that are custom made for a particular part or situation. Over the past decade, there in increase in mass production and has increased the demand for forged components. Wheel hubs being the major component in an automotive responsible for attaching the wheel. The work holding was the primary issue of the machining operation to be confronted. The objective of this paper describes the detailed definition of work holding devices and also identifies several benefits that are connected with the use of work holding in manufacturing that includes increase in production rate and cost reduction. Interchangeability and accuracy of machining parts which at most eliminates the need for inspection and quality expenses. It also describes the changeover from the traditional job holding technique towards the fixtures that can be controlled through CNC machines or VMC machines itself and serves the necessary purpose with minimal errors as there is not much of interference of human operators. Adapting this kind of simple and effective mechanism in fabrication and manufacturing sector drastically reduces the cost of labor and cycle time, thereby increasing the quantity and quality of production. This fixture assists the forged work piece used for the wheel hubs of an automobile for drilling and tapping at required positions. The forged component already manufactured needs to be drilled as per the drawings with respect to its orientation to perform the mentioned operations. To undergo the operation a special Colette system was designed and manufactured.
\end{abstract}

Keywords: Work-holding, Manufacturing, Production, Devices, Machining, Collet system. 
Cite this Article: Hamritha S, Rajesh B, Hemanth M, Design of Work Holding Device on Wheel HUB for Drilling of 5 LUG Bolts. International Journal of Mechanical Engineering and Technology 11(1), 2020, pp. 105-114. https://iaeme.com/Home/issue/IJMET?Volume=11\&Issue=1

\section{INTRODUCTION}

Locomotive industry is among the largest and quickest growing industries all over the world. The automotive industry includes automobiles, auto-component sectors, commercial vehicles, multi-utility vehicles, passenger cars, two-wheelers and auto related part. The people's search for manufactured goods is growing rapidly over the decade. Therefore, to meet the high demand by the customers, manufacturers have restored by inventing innovative ways of manufacturing high quality products at increasing rate. The production processes have witnessed numerous changes and evolution with the introduction of numerous innovative manufacturing concepts. The creative approaches have imposed the need for a reliable and cheaper tool.

As an effective manufacturing company, the demand for a prompt and simple work positioning strategy for correct operations which mostly depends on the interchangeability of machine parts and workpieces. To ensure reduction in complications in the assembly and innovation in the activities play a key role. By introducing the designed work holding device, it was observed that the correct positioning of the operations was carried out and rework were reduced.

The major activity of the present research is to introduce secured operating conditions, optimal load and cost reduction for the manufacture of wheel hubs in vehicles [3].

The wheel hub lies between brake drums and drive axle, helps in mounting for the wheel. The assembly contains bearings, which allow the wheels to roll quietly and efficiently. The hub assembly then fits on the axle, which connects the tire component and is the interface between wheels and rest of the vehicle. The objective is to design and manufacture a work holding to drill $12 \mathrm{~mm}$ diameter of 5 lug bolts of Pitch circle diameter $114 \mathrm{~mm}$ and reduce the cycle time for replacing the components to undergo the operations, as lug bolts are integral to hub, hence it is also called as locking bolts.

\subsection{Design Considerations}

The points that are taken into considerations for designing of this Collet system are as follows:

- The Collet system device should be sturdy and have high durability. The operations that includes are drilling and clamping of work piece to the machine table.

- Clamping of the component should be fast and accurate.

- Repositioning of job is made easier by providing spring action between LM Guideway and collet collar.

- Elimination of need for skilled operator.

- It has been preferred that there is a maximum operation in a single setting of the work holding device.

- Addition of guide ways for exact orientation with the component to prevent misalignment.

- The movement of the Collet system fixture is restricted and held in position by T-bolts on machine table. 
- Compression mechanism is adopted, i.e. the pressure was kept I between 50-120bar, which should not cause any harm to the component being held.

- The design should hold enough rigidity and robustness to prevent vibrations or else it may lead to undesirable movement of work piece and the tool.

The below Fig 1, Fig 2 and Fig 3 describes the design of the wheel hub component used in automotive applications. The component is made up of forged cast iron and weighs $1.300 \mathrm{~kg}$ which has youngs modulus upto $120 \mathrm{kN} / \mathrm{mm}^{2}$ and $7200 \mathrm{kgmm}^{3}$ as density.

\subsection{Components Details}

Table 1: Component Specification

\begin{tabular}{|l|c|}
\hline \multicolumn{1}{|c|}{ Specifications } & Dimension $(\mathbf{m m})$ \\
\hline Outer Diameter & 152dia \\
\hline PCD 114.3 & 12.1dia \\
\hline PCD101 & 29dia \\
\hline Inner diameter of the cut out & 64dia \\
\hline
\end{tabular}

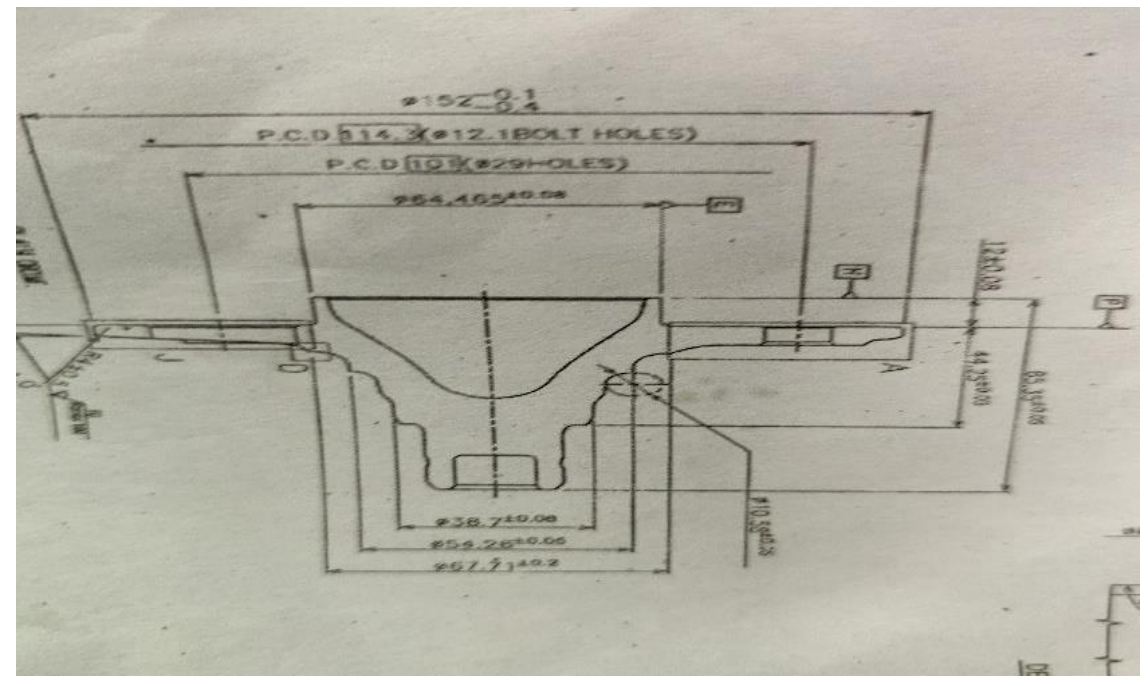

Figure 1 Component Design

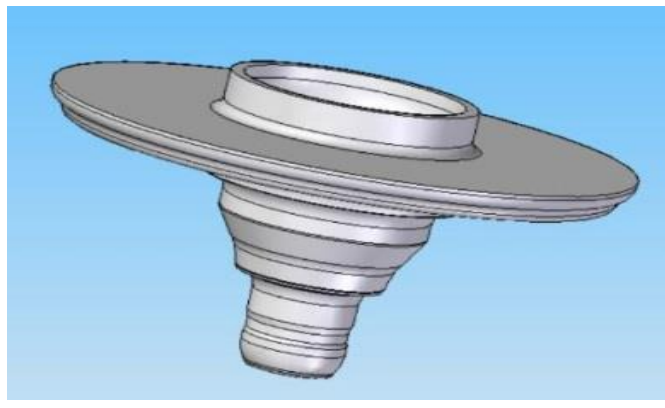

Figure 2 Forged component before drilling

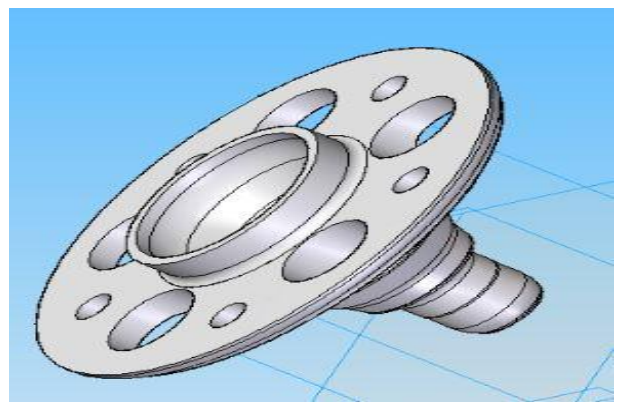

Figure 3: Finished Forged component after drilling 


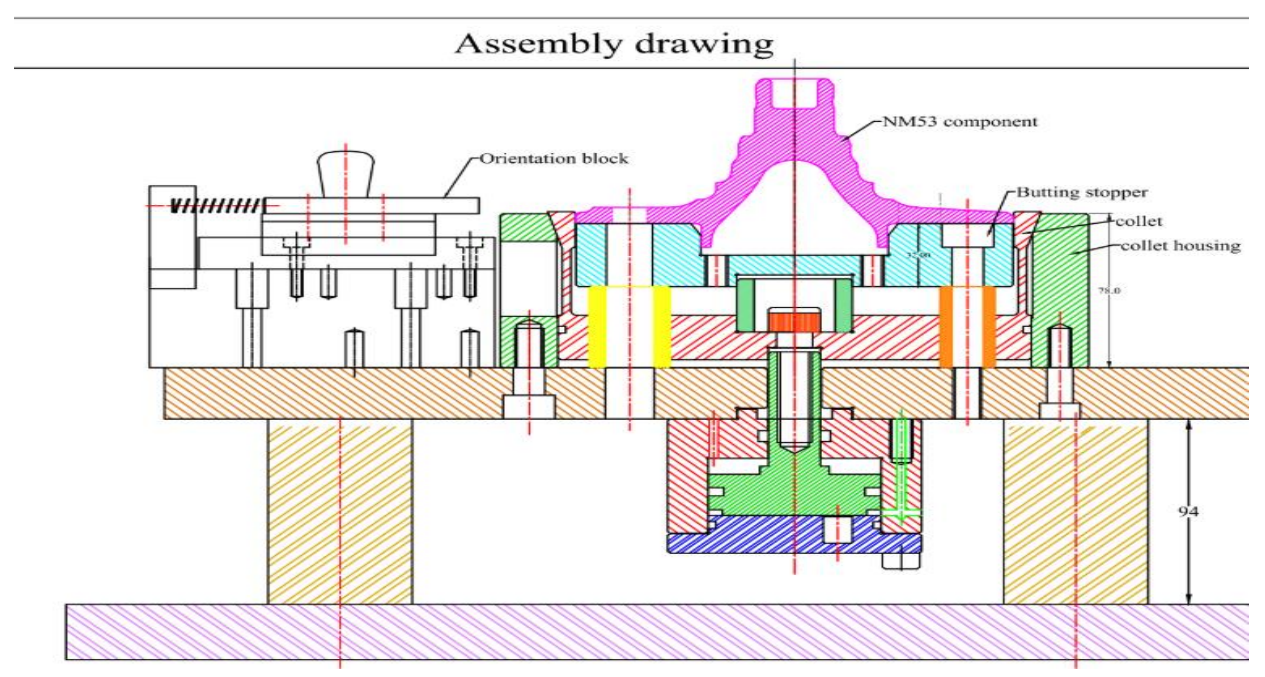

Figure 4 Assembled view

This is a detailed view of the assembly with all the subcomponents being mounted. This fixture is $60 \times 80 \mathrm{~cm}$ in size. The height of the pillars being $9.4 \mathrm{~cm}$. The fixture will rest on the bed of the machine by which it will operated. There is a cylinder of $6.3 \mathrm{~cm}$ in height which is placed inverted. The whole assembly has been manufactured considering desired mechanical properties. The pillars are mounted on the base plate with the help of bolts for easy removal and they are welded on the surface between the plate and the pillar. The pillars can withstand up to a weight of $230 \mathrm{~kg}$. The whole manufactured fixture is $80 \mathrm{~kg}$ in weight. There are 5 main components of the fixture being Supporting pillars, Collet housing, Collet, Butting stopper, Linear Motion Guideways. The fixture is designed with precision and accuracy considering the necessary design parameters.

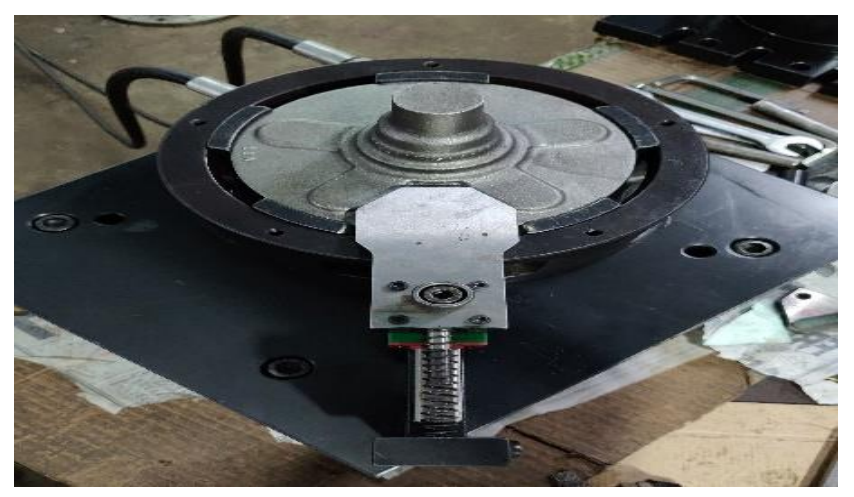

Figure 5 Original fixture with component

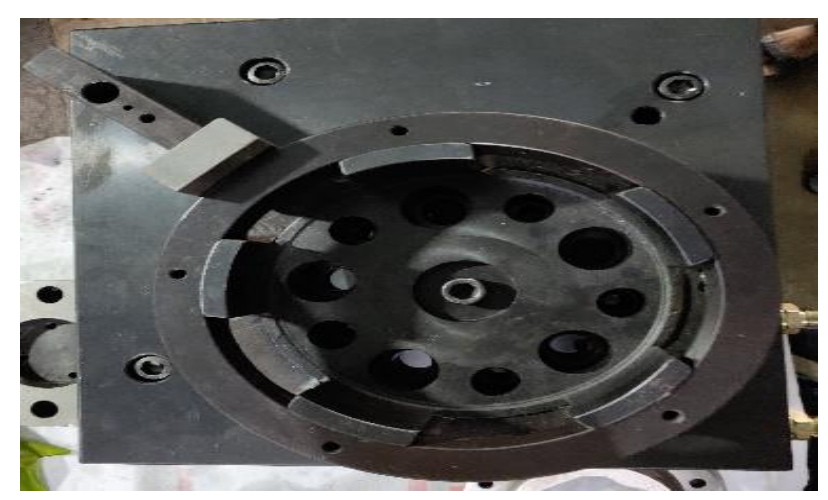

Figure 6 Original fixture without Component 


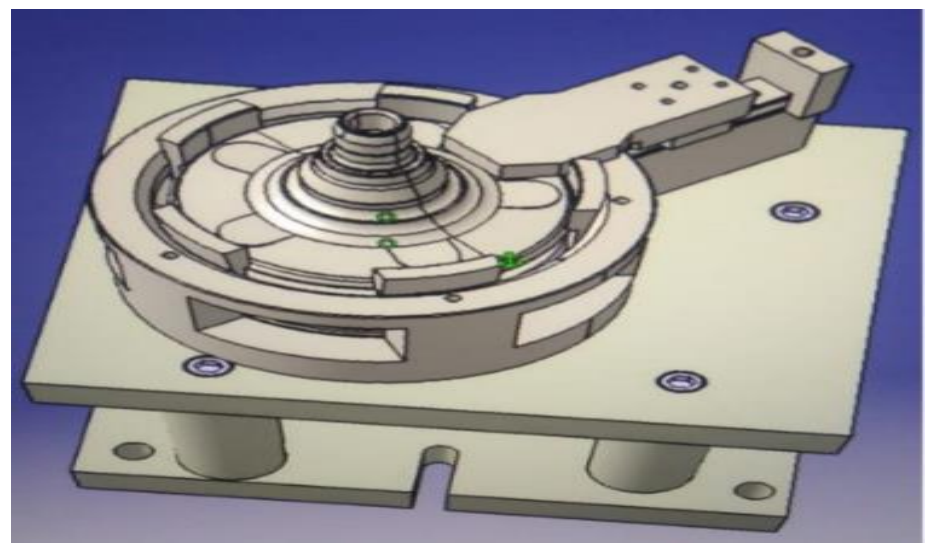

Figure 7: Final design of fixture

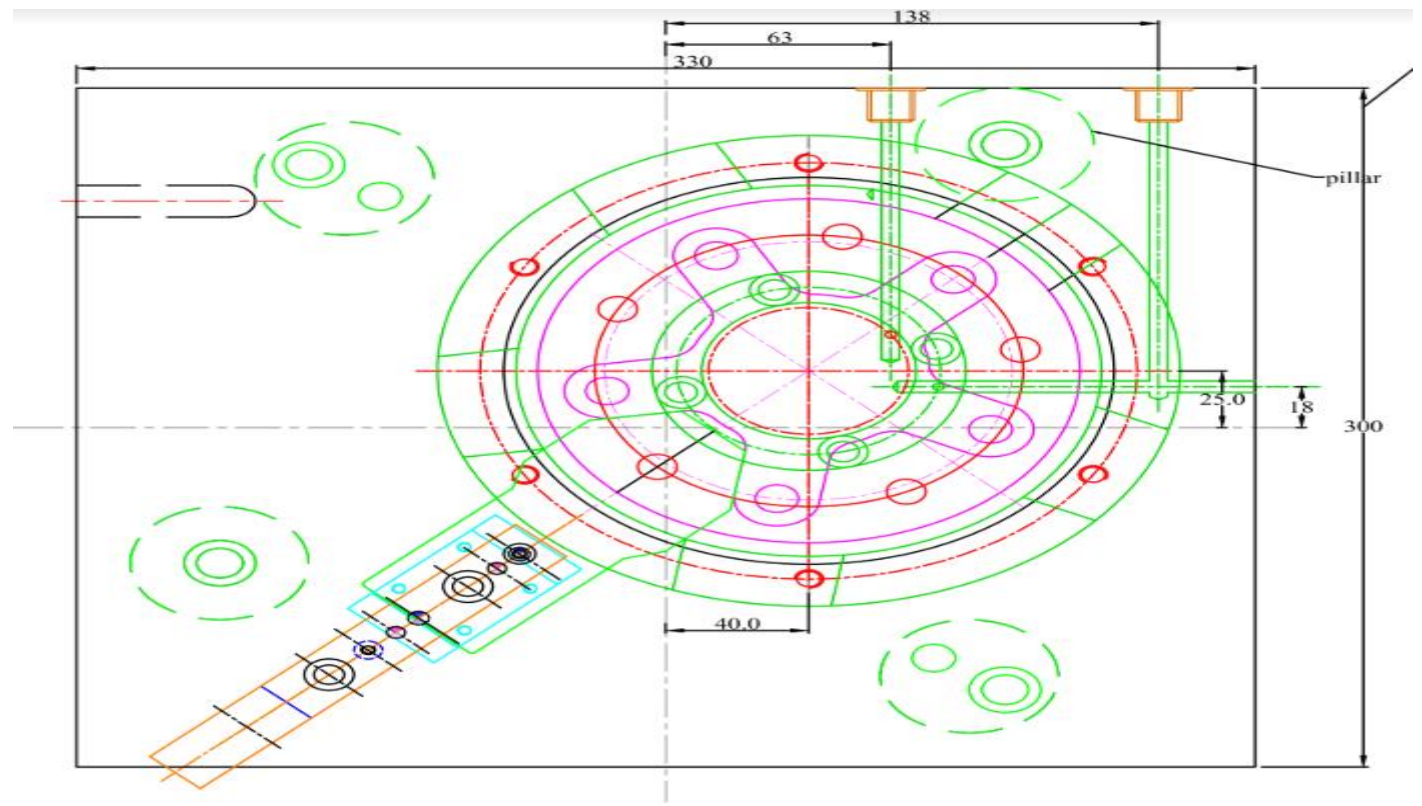

Figure 5 Top view of the Fixture

\subsection{Design of Collet Housing}

Collet housing is the outer covering for the collet. It has been divided into 5 sub pillars acting as airspaces holes of 72 degree each of $9 \mathrm{~mm}$ in size. The total diameter of the collet housing is $164 \mathrm{~mm}$. They are mounted on the upper base plate with 5 bolts. They have tapering angle of 15 degree and length of $10.2 \mathrm{~mm}$ from the upper surface. The base of the collet housing is $25 \mathrm{~mm}$. The material used here is forged iron undergoing various operations such as turning, milling, tapping and drilling. After all the operations being performed it undergoes blackening. 


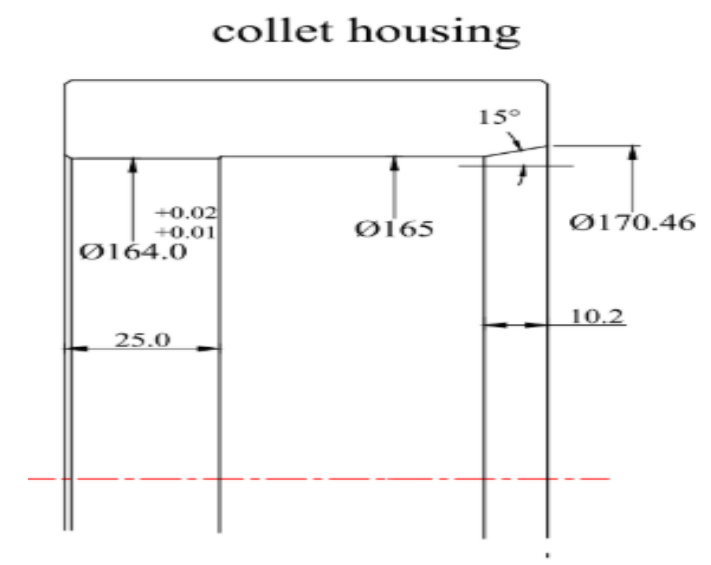

Figure 6 Dimensional view of collet housing

\subsection{Design of Collet}

Collet plays and important role in this fixture design. The collet is mounted on the butting stopper, inside the collet housing. The collet is made of cast iron. The total diameter of the collet is $164 \mathrm{~mm}$. There is a taper angle of $15^{\circ}$ and the taper length being $18.7 \mathrm{~mm}$. It is drilled with a hole is the center of $18 \mathrm{~mm}$ dia. Collet helps in contracting and relaxation of the component placed on the fixture on the application of force and pressure.

\section{collet}

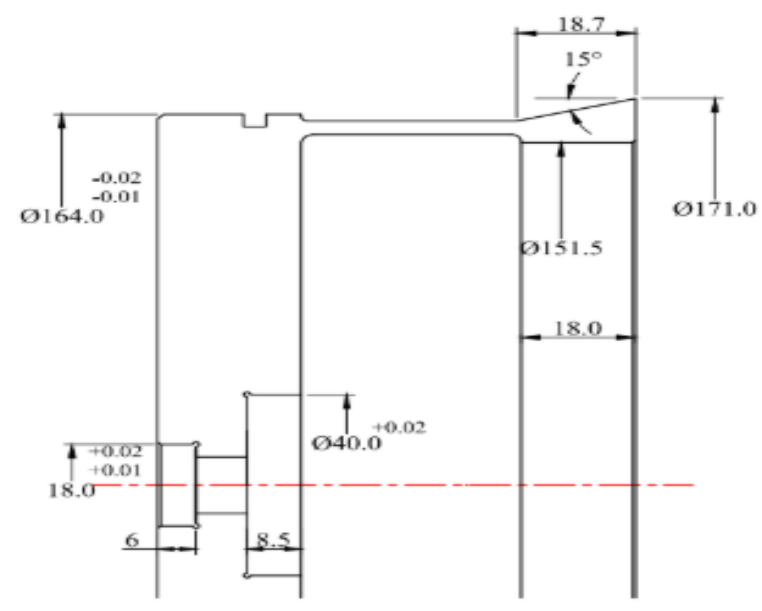

Figure 7 Dimensional view of collet

\subsection{Design of Butting Stopper}

Butting stopper is mounted inside the collet housing, it helps in clamping of collet on which it is placed. The diameter of the butting stopper is $151.5 \mathrm{~mm}$ and thickness is $32 \mathrm{~mm}$. There is $40 \mathrm{~mm}$ dia and $6 \mathrm{~mm}$ thickness hole drilled by which it is mounted on the collet housing. The upper surface of the butting stopper has a tapering angle of $30^{\circ}$. 


\section{Butting stopper}

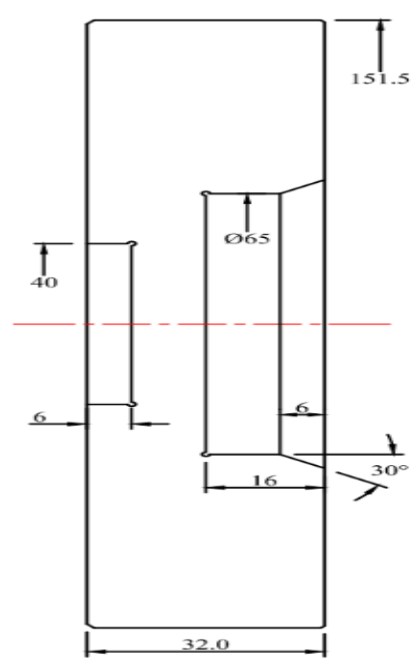

Figure 8: Dimensional view of Butting Stopper

\subsection{Design of Orientation Block}

The orientation block is manually designed for the fixture. The front side of orientation block is of hexagon is shape. It is fixed on Linear motion Guideways.They help in movement of linear motion by spring action. This helps in orienting the component with the fixture as soon as its palced, any slight corrections is managed by the orientation block. The total length of the block is $117.5 \mathrm{~mm}$. There is $34 \mathrm{~mm}$ thickness in depth for fixing on LM guideways. The total thickness of the orientation block is $6 \mathrm{~mm}$. There are 4 holes of $4.5 \mathrm{~mm}$ dia for fixing on LM guideways.

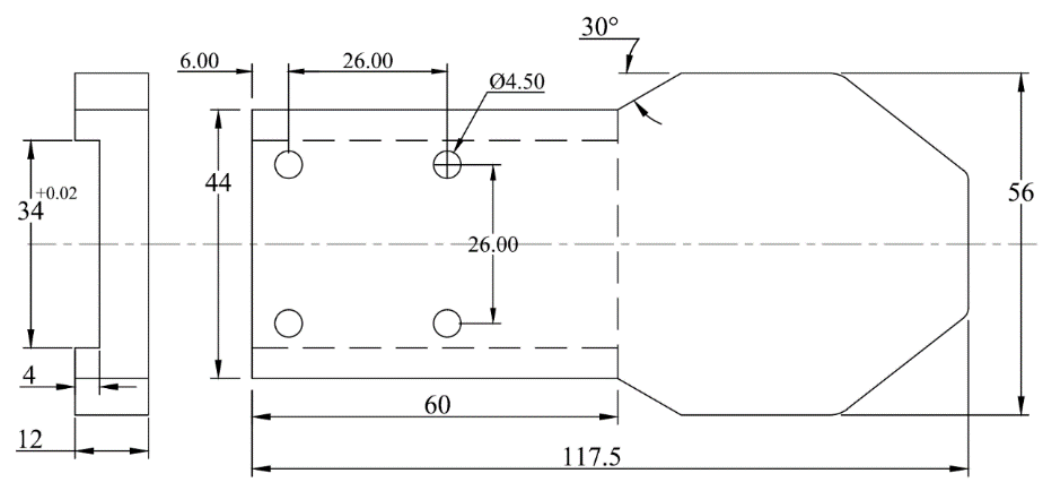

Figure 9 Dimensional view of orientation Block 


\title{
STEP WISE MANUFACTURING
}

\author{
OF 5 LUG BOLTS FIXTURE
}
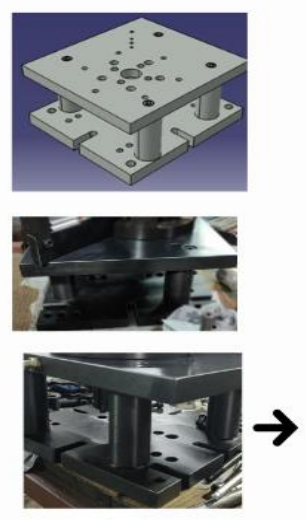

1

SUPPORTING

PILLARS

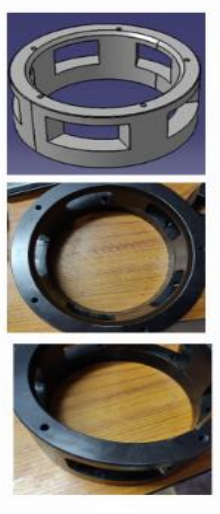

2

COLLET HOUSING

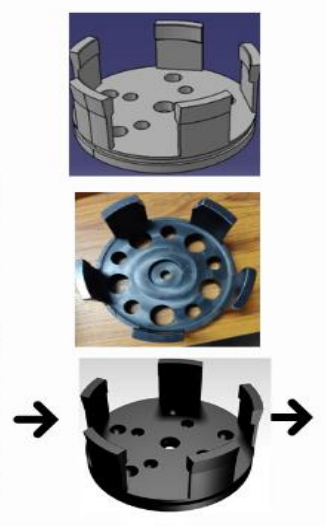

3

COLLET
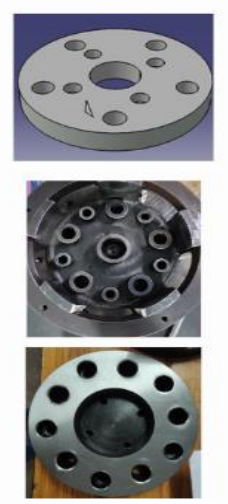

4

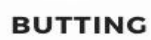

STOPPER
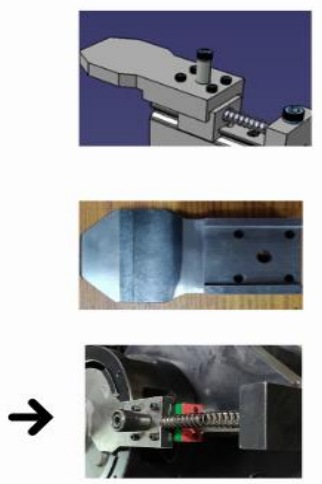

5

LM GUIDE WAYS \& ORIENTATION BLOCK

Figure 10: Manufacturing details of the 5 Lug Bolt Fixture

\section{DISCUSSION ON DESIGN PARAMETERS FOR WHEEL HUB DRILLING USING THE WORK HOLDING}

The hub designed has to fit the left and right side of drive motors, which offers dual benefit: firstly, it creates a proof on one part and secondly, it avoids the process of inspection. With this process it clearly states that the correct positions for drilling to carry out the operations.

In this fixture collet acts as chuck and is not identical. When a chuck is tightened around the component being held, a collet uses clamping pressure by forming a collar around the object being held, holding it firmly in place. This clamping force is typing applied through a narrowing design that uses a cover and inner cylindrical surface. There are various designs, but the collet types operate on pressing it over the element to be held and resulting in both precise alignment and fixed friction. But the concept of collet is not suitable for all the tools and operations, it has resistance against loosening, manages to self-centering and fastchucking.

At the start of the design no optimization point is considered for the hub. Initially Hub was designed and manufactured according to the requirement. The basic design of the hub is according to the bearing sizes which are selected. Hub consists of 5 lug bolts which are connected to the rim of the wheel. Hence the holes are selected according the pitch circle diameter of the rim.

The main objective of doing optimization is to drill 5 lug bolts holes and reduce the cycle time for replacing the forged component to undergo the operation and increase the rate of components manufactured in a batch.

\subsection{Procedure}

The fixture was made of forged cast iron, which was mounted on t-slots. This work holding device was very much useful in the VMC and CNC. The objective was to drill 5 lug bolts of $12 \mathrm{~mm}$ in diameter at equal distance from the center. The time taken by an operator to place 
and orient the component was less than $12 \mathrm{sec}$, this increased the cycle time in mass production while manufacturing.

\section{DISCUSSIONS}

The design of fixture mainly depends on the type of operation and machine tool considered for the process. They are designed to eliminate the need for a exceptional set-up time for every workpiece the component being placed. Thereby this process increases the production and assures that every work piece is manufactured within a fixed tolerance limit. There is removal of many activities to name a few needs for marking out, punching and positioning. This at most reduces the set up time for each work-piece and also reduces the cycle time of the process by increasing technological capacities of machine tools, setting of higher values of some operating capability conditions.

\section{CONCLUSION}

The purpose of this paper is to design and manufacture the 5 lug bolt holes of the wheel hub for the car and also to provide a detailed study in the process taken to reach the required design of the work holding device. The main objective was to reduce the cycle time in precise orientation of the component. With the overall design being carefully examined in advance, the manufacturing process is closely controlled design features are proven efficient within the required performance.

\section{REFERENCES}

[1] Nanthakumar, K. and Prabakaran, V. "Design and Fabrication Testing of Combined Multipurpose Jig and Fixture" IOSR Journal of Mechanical and Civil Engineering, 2014

[2] Lin, Q., Burdick, J., and Rimon, E. "Constructing Minimum Deflection Arrangements Using Invariant Norms" IEEE Transactions on Automation Science and Engineering, Vol. 32006

[3] S.Dhar "Fracture analysis of wheel hub fabricated from pressure die Aluminum assembly theoretical and applied fracture mechanics" vol 9 Feb 1988

[4] Bhushan Mohinte "Stres Analysis and Optimization of Front Wheel Hub" International Journal for Research in Applied Science and Engineering" Vol 6, Issue 10, Oct 2018

[5] Sachin S Natu et al, "Design and Analysis of Wheel Hub" IJIERT - ISSN No - 2394 3696, Feb - 2019

[6] J Fleischer et al, "Workpiece and tool handling in metal cutting machines" CIRP Annals, Vol 55, 2 2006, Pages 817-839

[7] A Gameros et al, "State-of-the-art in fixture systems for the manufacture and assembly of rigid components: A review" International Journal of Machine tools and Manufacture Vol 123, 2017, Pages 1-21

[8] Bankole 1 Oladapo et al, "Experimental analytical design of CNC machine tool SCFC based on electro-pneumatic system simulation" Engineering Science and Technology, an International journal, Vol 19, 4, 2016, Pages 1958-1965

[9] Hans - Christian et al, "Intelligent Fixtures for High Performance Machining" Procedia CIRP, Vol 46, 2016, pages 383-390

[10] S Vajpayee et al, "Selection of work piece size for accurate turning" Wear, Vol 67, 1, 1981, Page 107-113

[11] Daoh-Tiarn Zhang et al, "An NC lathe simulator for part programming and machine operation training" Computers in industry, vol 21, 2, 1993, Pages 139-148 
[12] A K Chitta, et al, "A decision support system for process planning" Computers in Industry, Volume 14, Issue 4, 1990, Pages 307-318

[13] Alexandra Mironova et al, "Robust control using sliding mode approach for ice-clamping device activated by thermoelectric coolers" IFAC-Papers Online 49-25 2016 pages 470475

[14] Prof Mr Uday C Agashe et al, "Study of fixture and its modifications" IJRASET, Vol 6, 4, 2018, pages 728-733

[15] A Saravanakumar et al, "Analysis of process parameters in surface grinding process" Materials Today Proceedings, Vol 5, 2, Part 2, 2018, Pages 81231-8137 